\title{
Effect of microorganisms on etiology of hematospermia
}

\author{
Musa Saracoglu ${ }^{1}$, Hakan Ozturk ${ }^{1}$, Arzu Duran ${ }^{2}$, Sabri Atalay ${ }^{3}$ \\ Departments of ${ }^{1}$ Urology and ${ }^{2}$ Microbiology, School of Medicine, Sifa University, Izmir, Turkey; \\ ${ }^{3}$ Department of Infectious Diseases and Clinical Microbiology, Tepecik Education and Research Hospital, Izmir, Turkey.
}

\begin{abstract}
Summary Background: Hematospermia is the presence of blood in the ejaculate. Its etiology is congenital, inflammatory, infectious, obstructive, tumoral, vascular, traumatic, iatrogenic or related to systemic disease. It is a quite irritating and life-quality-disturbing condition for men. It is significant to demonstrate infectious-based hematospermia due to the fact that its treatment is easier than for other reasons.

Methods: 30 patients, having spontaneous hematospermia, were taken to our study. The serum total PSA levels of the patients were examined and microbiological examinations such as direct inspection for ejaculate, routine bacteriological and mycetes culture, Gram staining, trichrome staining and Mycoplasma hominis/Ureaplasma urealyticum culture (Mycofast Evolution 3, ELITech, France) were performed. Results: Bacteria was isolated in 11 (36\%) of 30 patients with hematospermia. S.aureus occurred in five patients (45.5\%), U.urealyticum in three patients $(27.2 \%)$ and E.coli and K.pneumoniae in one each (9.1\%). U.urealyticum and S.aureus occurred together in one patient. No statistical difference of scores of National Institute of Health-Chronic Prostatitis Symptoms Index (CPSI) and serum total PSA levels between the patients with and without infection was observed.

Conclusions: Hematospermia mostly affects micturition functions of young men and it can be due to infection in one-third of the cases.
\end{abstract}

KEY WORDS: Hematospermia; Ejaculate; PSA.

Submitted 24 October 2014; Accepted 30 November 2014

\section{INTRODUCTION}

Hematospermia is presence of blood in the ejaculate. It is known that is etiology can be congenital, inflammatory, infectious, obstructive, tumoral, vascular, traumatic, iatrogenic and systemic disease related (1). However, its cause cannot be determined in some cases that are considered as idiopathic hematospermia (2). In this study we aimed to investigate the rate of infectious etiology in the patients with hematospermia observed in a 3-year period.

\section{Patients and Methods}

Cases with spontaneous hematospermia were considered in the study. Patients with hematospermia subsequent to prostate biopsy or transurethral instrumentation were excluded from the study being considered as iatrogenic hematospermia. All the patients were scored according to National Institute of Health-Chronic Prostatitis Symptoms Index and were inspected. The levels of serum total PSA (Elecsys ${ }^{\circledR}$ total PSA, Roche/Hitachi, USA) were measured and microbiological evaluations of ejaculates were made. Microbiological evaluations were made according to the prostatitis panel created in our hospital. This panel is directed to evaluation of presence in the ejaculate of bacteria, fungus, parasite and leucocytes and includes direct microscopy and microscopy made after Gram and trichrome staining. It includes aerobe bacteria, mycetes, Mycoplasma hominis and Ureaplasma urealyticum (Mycofast Evolution 3, ELITech, France) cultures. Ejaculate samples used for microbiological evaluations were taken by masturbation after cleaning of glans penis and without using lubricant. Samples were seeded in sheep blood agar, EMB agar and Sabouraud Dextrose Agar (SDA) and incubated for 48 hours in an ambient of 350C-10\% $\mathrm{CO}_{2} ; 100 \mu \mathrm{L}$ of ejaculate was taken for Mycoplasma hominis and Ureaplasma urealyticum evaluation by Mycofast Evolution method.

Student $t$ test was performed in order to determine difference of total PSA levels and National Institute of Health-Chronic Prostatitis Symptoms Index scores among sub-groups.

\section{RESULTS}

Thirty patients were considered in the study. Five of them were single and the others were married. The ages of the patients ranged from 17 to 61 and the average was $37.21 ; 70 \%$ of the patients was under the age of 40 and $9(30 \%)$ of them were over 40. Data of National Institute of Health-Chronic Prostatitis Symptoms Index scores were reported in Table 1 in relation to microbiological findings. Bacteria were demonstrated in 11 (36\%) of 30 patients having hematospermia. No statistical difference of National Institute of Health-Chronic Prostatitis Symptoms Index scores was observed between patients with and without demonstration of infection.

At urological examination, BPH findings were observed in 4 patients. All these patients were over 40 years of age. There was no finding suspect of malignity in patients. Serum total PSA values varied between $0.26 \mathrm{ng} / \mathrm{mL}$ and $2.65 \mathrm{ng} / \mathrm{mL}$ and the average was $0.92 \mathrm{ng} / \mathrm{mL}$. Serum total 


\section{Table 1.}

National Institute of Health-Chronic Prostatitis Symptoms Index scores and serum total PSA values according to bacteria reproduction on patient samples.

\begin{tabular}{|l|c|c|c|c|}
\hline & $\begin{array}{c}\text { All } \\
\text { patients }\end{array}$ & $\begin{array}{c}\text { Bacteria } \\
\text { reproduction }\end{array}$ & $\begin{array}{c}\text { No bacteria } \\
\text { reproducion }\end{array}$ & $\mathbf{P}$ \\
\hline Pain score & 4.80 & 5.82 & 4.21 & 0.407 \\
Micturition score & 2.07 & 2.09 & 2.05 & 0.189 \\
Effect-quality score & 4.50 & 5.18 & 4.11 & 0.951 \\
Total score & 11.27 & 12.55 & 10.53 & 0.783 \\
Total PSA & 0.92 & 0.96 & 0.89 & 0.680 \\
\hline
\end{tabular}

\section{Table 2.}

National Institute of Health-Chronic Prostatitis Symptoms Index scores and serum total PSA values of patients by class ages.

\begin{tabular}{|l|c|c|c|c|}
\hline & All patients & $\mathbf{>} \mathbf{4 0}$ years & $\mathbf{<} \mathbf{4 0}$ years & $\mathbf{P}$ \\
\hline Pain score & 4.80 & 4.00 & 5.14 & 0.608 \\
Micturition score & 2.07 & 0.89 & 2.57 & 0.011 \\
Effect-quality score & 4.50 & 3.67 & 4.86 & 0.630 \\
Total score & 11.27 & 7.89 & 12.71 & 0.070 \\
Total PSA & 0.92 & 1.35 & 0.74 & 0.027 \\
& & & & \\
\hline
\end{tabular}

value averages of the patients with and without bacteria growth were reported in Table 1.

There was no significant difference in the statistical comparisons of two groups.

Bacteria growth was obtained in $11(36.7 \%)$ of 30 patients according to microbiological evaluations. Two bacteria were isolated in one patient. Out of 11 patients with bacteria isolates, Staphylococcus aureus was present in 5 patients (45.5\%), (three of them were MRSA and two of them were MSSA), Ureaplasma urealyticum in 3 patients (27.2\%), Escherichia coli and Klebsiella pneumoniae in one patient each (9.1\%) and association of Ureaplasma urealyticum and Staphylococcus aureus (MSSA) in another patient (9.1\%).

Table 2 shows findings obtained when the patients were separated in two groups under and over 40 years of age. Serum total PSA values of the patients over 40 age were significantly higher. Contrary to the expectations, micturition score of National Institute of Health-Chronic Prostatitis Symptoms Index was significantly higher in the patients under 40 age.

\section{Discussion}

Hematospermia is a symptom known for thousands of years, being present in the written sources of the Hippocrates period (3). Although it is generally considered as the result of benign conditions, in a study hematospermia was observed in 14\% of the prostate cancer patients (4). Prostate biopsy, used in the diagnosis of prostate cancer, has become the iatrogenic reason of hematospermia, which occurred more frequently in the last years (5). It is not possible to estimate the period of hematospermia on these patients (6). In order to foresee malign conditions age of the patient, coexistence of hematuria and type of hematospermia, persistent or recurrent, can be taken into consideration. The possibility of malign disease occurrence is higher in the individuals over $40(7,8)$. Hematuria can accompany with bladder, kidney and urethra malignancy as well as prostate malignancy. Compelete evaluation is required for the patients having hematuria (9).

In our study, as expected, serum total PSA values of the patients over 40 years was higher. On the contrary it was not expected that micturition score of the patients under 40 was higher. This can be explained by an exaggerated perception of pain in the younger patients. Anxiety, caused by hematospermia, is more apparent in young patients, therefore, it can cause an exaggerated perception for the symptoms.

One of the most frequent reasons of hematospermia is infection. Hematospermia can be observed especially in presence of infectious diseases of prostate (10). Infection-based hematospermia tends to recover in a short time and is non-recurrent. In a study on 170 patients having hematospermia, chronic prostatitis rate was determined as 14\% (11). In other study, on 67 patients evaluated, chronic prostatitis was diagnosed in 28\% (12).

In our study, infectious factors were demonstrated in $36 \%$ of the patients. The reason of this higher rate respect to the literature is the potential of our analysis panel to demonstrate a wide spectrum of microorganisms. Especially, the use of tests for evaluation of Mycoplasma hominis and Ureaplasma urealyticum explains this situation. It is not possible to define characteristics of patients with bacterial isolation because there was no significant difference in clinic symptoms of the patients with or without infection.

So, microbiological evaluation of the patients having hematospermia is important in order to determine the underlying pathological condtion.

In conclusion, infectious causes have a significant place in the patients having hematospermia.

While evaluating the patients having hematospermia, non-invasive and low-cost microbiological evaluations within the first evaluation are significant in order to understand the underlying reason and to apply a more effective treatment.

\section{REFERENCES}

1. Kumar P, Kapoor S, Nargund V. Haematospermia - a systematic review. Ann R Coll Surg Engl. 2006; 88:339-42.

2. Magoha GA, Magoha OB. Aetiology, diagnosis and management of haemospermia: a review. East Afr Med J. 2007; 84:589-94.

3. Mulhall JP, Albertson PC. Haemospermia: diagnosis and management. Urology. 1995; 46:463-7.

4. Han M, Brannigan RE, Antenor J-AV, et al. Association of hemospermia with prostate cancer. J Urol. 2004; 172:2189-92.

5. Manoharan M, Ayyathurai R, Nieder AM, Soloway MS. Hemospermia following transrectal ultrasound-guided prostate biopsy: a prospective study. Prostate. Cancer Prostatic Dis. 2007; 10:283-7.

6. Abdelkhalek MA, Abdelshafy M, Elhelaly HA, El Nasr MK. 
Hemospermia after transrectal ultrasound (TRUS)-guided prostatic biopsy: a prospective study. J Egypt Soc Parasitol. 2012; 42:63-70.

7. Leocádio DE, Stein BS. Hematospermia: etiological and management considerations. Review. Int Urol Nephrol. 2009; 41:77-83.

8. Ahmad I, Krishna NS. Hemospermia. J Urol. 2007; 177:1613-8.

9. Polito M, Giannubilo W, d'Anzeo G, Muzzonigro G. Hematospermia: diagnosis and treatment. Arch Ital Urol Androl. 2006; 78:82-5.
10. Klevecka V, Jatulis A, Kraniauskas V, et al. Hemospermia; Medicina (Kaunas) 2005; 41:359-64.

11. Jinza S, Noguchi K, Hosaka M. Retrospective study of 107 patients with hematospermia. Hinyokika Kiyo. 1997; 43:103-7.

12. Kochakarn W, Leenanupunth C, Ratana-Olarn K, Viseshsindh $V$. Hemospermia: review of the management with 5 years follow-up. J Med Assoc Thai. 2001; 84:1518-21.

\section{Correspondence}

Musa Saracoglu, MD Asst Prof musasaracoglu@yahoo.com

Hakan Oztürk, MD. Asst.Prof. (Corresponding Author) drhakanozturk@yahoo.com.tr

Basmane Hospital of Sifa University

Fevzipasa Boulevard No: 172/2, 35240, Basmane-Konak-Izmir, Turkey

Arzu Duran, MD Asst Prof

arzu.duran@sifa.edu.tr

Bornova Hospital of Sifa University

Sanayi Street No: 7, 35100, Bornova-Izmir, Turkey

Sabri Atalay, MD

drsatalay@yahoo.com

Tepecik Education and Research

Hospital Department of Infectious Diseases and Clinical Microbiology Gaziler Street No:468 35120 Yenisehir, Konak, Izmir, Turkey 